\title{
Development of sensitivity to static pictorial depth information*
}

\author{
CATHERINE BENSONं and ALBERT YONAS $\dagger+$ \\ University of Minnesota, Minneapolis, Minnesota 55455
}

\begin{abstract}
Sensitivity to the pictorial depth cues of shading, linear perspective, and position on the picture plane were investigated with children from 3 to 7 years of age as well as with adults. Using a discriminative learning method, all Ss were found to be sensitive to shading information for depth when the display was oriented vertically, but not when it was oriented horizontally. In addition, binocular view did not decrease sensitivity relative to monocular view. Linear perspective was found to be effective in controlling 3-year-olds' size discriminations of equal-area figures, while position on the picture plane was ineffective in the absence of other information for depth.
\end{abstract}

The purpose of this study was to assess sensitivity in young children to a number of static pictorial depth cues. The two traditional theories of development of depth perception are presented in Hochberg's (1962) excellent review, "Nativism and Empiricism in Perception." A third point of view is a mixture of the two theories: while some primary depth cues (motion and binocular parallax) have an innate basis and are effective by the second month of life, the secondary or pictorial depth cues are learned rather slowly (Bower, 1966). Some recent research supports this position.

Bower $(1964,1965,1966)$ found that infants as young as 40 days of age were sensitive to depth information provided by primary cues of motion and binocular parallax but were insensitive to static pictorial depth information. Similarly. Wilcox and Teghtsoonian (1971) detected no evidence of sensitivity to pictorial depth information in 3-year-old Ss. On the other hand, Hochberg and Brooks (1962) found that a 19-month-old child raised with no pictorial experience could name common objects in line drawings and photographs. While this suggests that some sensitivity to pictorial information is innate, it is not necessarily evidence that depth is being detected. The child may have recognized the objects on the basis of their silhouettes or two-dimensional shapes.

In a study based on the findings of Wilcox and Teghtsoonian. Yonas and Hagen (in press) tested the hypothesis that sensitivity to pictorial information is present in 3-year-olds but is suppressed because young $\mathrm{Ss}$

* This research was supported in part by a grant to the second author from the National Institute of Child Health and Human Development (1 P01 HD05027). Experiment I was reported as a Senior Honor Thesis by the first author under the supervision of the second author.

$\div$ Now at the Lniversity of Massachusetts, Amherst, Massachusetts.

$\div+$ Reprint requests should be sent to Albert Yonas. Institute of Child Development, University of Minnesota. Minneapolis. Minnesota 55455 . attend to information for the picture plane while older Ss ignore it. Using a rear-projected slide, they found some sensitivity to texture gradient information for depth and evidence that this sensitivity increases with age. In addition, children responded less often to pictorial depth when motion parallax information for the picture plane was present than when it was absent.

The purpose of the present study was to investigate the development of sensitivity to other pictorial cues. Photographs were used in Experiments I and II to study shading as a cue to relative depth. In Experiment III, the effectiveness of line drawings with strong linear perspective information was investigated.

\section{EXPERIMENT I}

When the source of illumination is known, the areas of light and shade on an object can specify its relief. It has long been noted that if shading provides the only information for relative depth in a picture, the relief of the surface can reverse when the picture is inverted, turning a crater into a mound (Gibson, 1950, p. 97). The result suggests that Ss continue to "assume"1 that the source of illumination is from above when the picture is inverted. Metzger (1936) argued that this assumption is acquired quite late in development. Research with animals provides conflicting information on the question. Hess (1950) found that chicks reared with light from below would, when presented with a photograph. tend to peck at corn that cast shadows above rather than below. In contrast, Hershberger (1970) found that early experience with light below had little effect on chick's perception of displays such as Fig. 1. They behaved as if the light came from above. The only research on the phenomenon with children was a study in which Von Fieandt (1938) tested six children from 4 to 7 years of age and found the effect was similar to that found in adults.

In the present study, 3-. 5-. and 7-year-olds were asked to discriminate convexities from concavities using 


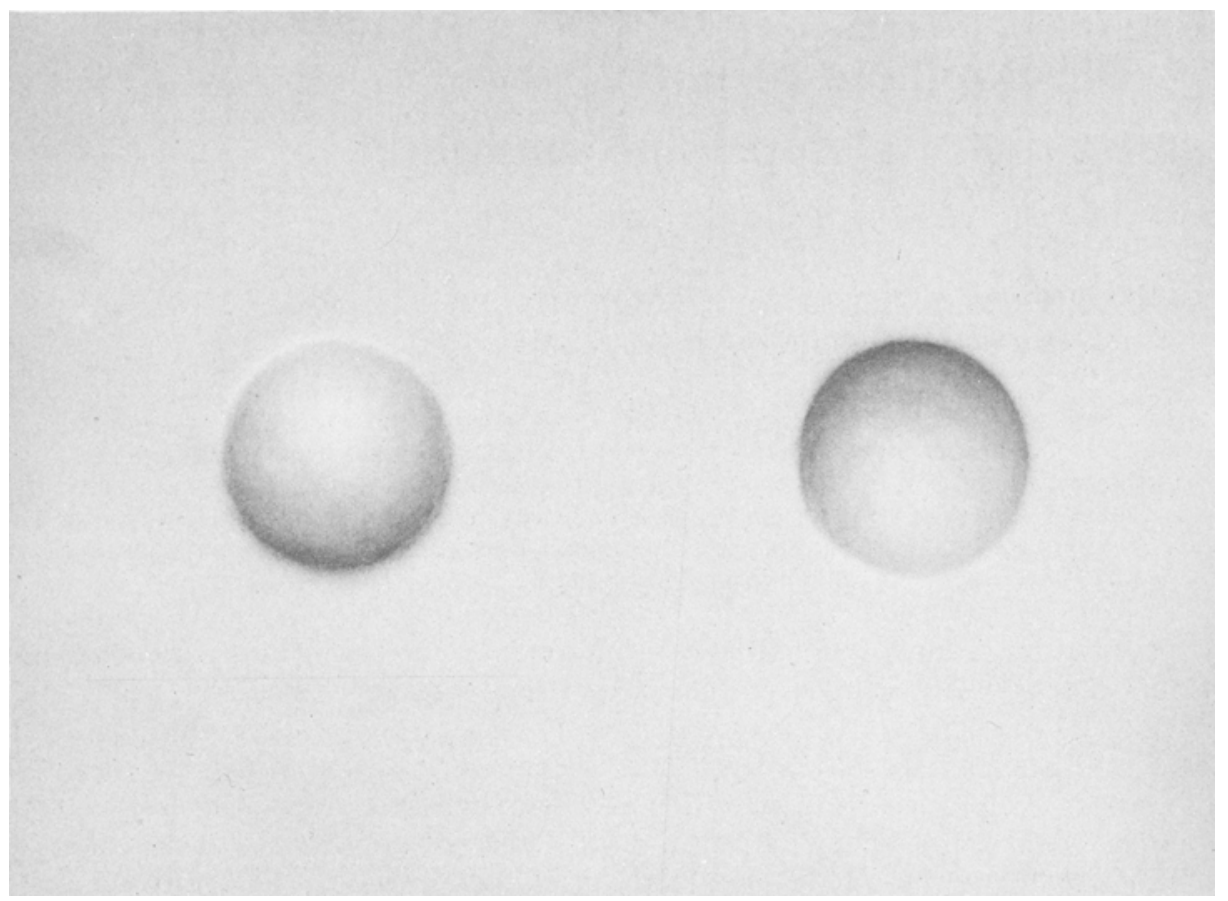

Fig. 1. Photograph of convex and concave shapes.

a photograph in which the relationship between shading and the assumed source of illumination provided the only information for depth (see Fig. 1). In addition, we contrasted monocular and binocular presentation to investigate the possibility that young children would be less responsive to shading information if conflicting information from the picture plane was present.

To assess sensitivity, children were first trained with feedback to discriminate a real convexity from a concavity using binocular parallax and occasional tactile information. The lighting was arranged to eliminate shadows. They were then tested with a photograph of the forms in which shading provided the only information for the difference in shape.

\section{Method}

\section{Subjects}

Sixty middle-class children from Fort Collins, Colorado, served as $S s$ in this experiment. Three age groups were used. The youngest group was made up of 20 nursery school children, who ranged in age from 36 to 47 months, with a mean age of 42 months. The middle group was made up of 20 kindergarten children from a public school. They ranged in age from 61 to 71 months, with a mean age of 67 months. The oldest group were 20 second graders, who ranged in age from 84 to 93 months, with a mean age of 87 months. Within each age group, there were 10 boys and 10 girls. Thirteen Ss were unable to learn the initial discrimination and did not complete the experiment. Ten of these children were in the youngest age group, two in the middle group, and one in the oldest age group.

\section{Apparatus}

The stimuli were presented to the $S s$ in a box that excluded light from the room and had built-in lighting arranged so that shadows were eliminated. A viewing hood was used to position the Ss' eyes $13 \mathrm{in}$. from the display. The hood was adjusted to one side in the monocular condition so that the preferred eye was centered on the display. There was a response button on each side on the top of the box with which the $S$ indicated a form's position and a light above the box that came on to indicate a correct response. In addition, a door in the side of the box could be opened to allow the $S$ to feel the three-dimensional display.

During an initial response training period, Ss viewed a $5 \times 7$ in. card with a picture of a doll glued on the right and a picture of a car on the left. On a second card, the positions of these toys were reversed. During discrimination training, Ss viewed a gray, matte-finished copper rectangle in which a circular convexity and concavity, $1 \frac{11 / 4}{\mathrm{in}}$. in diam and $1 / 4$ in. deep, had been molded. The plate was inverted to reverse left-right positions. In the test phase, a photograph of this rectangle in direct light and with distinct shadows was viewed (see Fig. 1). To reverse the position of the forms, a second print was made with a reversed negative.

\section{Procedure}

Ss were asked to look into the viewing box and were shown a card on which pictures of two toys had been glued. Ss were then asked which toy they preferred and told to push the button on the same side as that toy. The positions of the toys were varied randomly until five consecutive consistent choices had been made. During training, a correct choice resulted in the indicator light's coming on and an M\&M candy reward. When response training reached criterion, Ss were shown the rectangle with the convexity and concavity in the viewing box and asked which shape they preferred. They were then instructed to push the button on the same side as the "bump" or "hole," depending on this preference. Many of the youngest Ss could not initially discriminate the shapes using only binocular parallax. When this was true, they were allowed to feel the shapes. The positions of the shapes were varied randomly on each trial until the $S$ had reached the criterion of five consecutive correct choices. 
When a $S$ reached criterion on discrimination training, he was given 20 test trials, 10 monocular and 10 binocular, with the order of conditions counterbalanced within each sex and age group. During testing. Ss were told. "Good," after every response. If a S's preferred shape during discrimination training was a convexity, a correct testing choice was the form with its top brightly lit and its bottom shaded. If a concavity was the preferred shape, a correct response required the choice of form with shading reversed.

\section{Results}

The number of correct choices out of a possible 10 is presented in Table 1. A four-way analysis of variance, in which age, sex, and order were between-Ss factors and monocular vs binocular view was a within-Ss factor, was carried out on these data. Only age was a significant source of variance $[F(2,48)=4.16, p<.05]$. A Scheffé confidence interval for multiple comparisons (Guenther, 1964) was computed for these data and revealed that the difference between the performance of the 3- and 7 -year-olds was significant $(p<.01)$. In addition, all age groups responded significantly higher than chance (Scheffé test, $\mathrm{p}<.01$ ). Monocular and binocular performances were not significantly different.

\section{Discussion}

Sensitivity to shading information for depth was present in all age groups. Although 3-year-olds had an average error rate of $30 \%$, they were still significantly higher than chance. The error rate of the 7-year-olds was only $12.5 \%$, suggesting that sensitivity to shading information improves with age. On the other hand, seven of the Ss in the youngest group were nearly perfect in performance (two or fewer errors in 20 trials). The 3-year-olds with higher error rates often alternated responses or pressed the same button consistently. It is likely that they were not attending to the task.

The information for flatness of picture plane provided by binocular parallax did not suppress sensitivity in any age group. Preschool children may have already learned to ignore conflicting stereoscopic information when viewing pictures. Alternatively, in this situation, binocular parallax may be a much weaker depth cue than is shading, and thus generates little conflict.

\section{EXPERIMENT II}

The purpose of this experiment was to see if the generally poor performance of the youngest Ss was due to insensitivity to shading information or to an inability to maintain attention during a very long task. To shorten the length of the experiment and to eliminate the response training phase, the viewing box was discarded and $S s$ responded by pointing to the preferred shape rather than pressing the appropriate button. Also, haptic discrimination training replaced the very difficult visual discrimination training with binocular parallax as the only visual depth cue.
Table 1

Mean Correct Responses Out of 10 Trials

\begin{tabular}{ccc}
\hline & \multicolumn{2}{c}{ Condition } \\
\cline { 2 - 3 } Age & Binocular & Monocular \\
\hline 3 & 6.95 & 7.05 \\
5 & 8.35 & 8.30 \\
7 & 8.85 & 8.90 \\
\hline
\end{tabular}

In the terrestrial environment in general, and in our experimental room in particular, light comes from above. A convexity on a vertical surface will be brightly lit on top and its bottom will be shaded; the reverse is true of a concavity. But on a horizontal surface there is no lawful relationship between the shading of areas and shape unless the source of illumination is specified. ${ }^{2}$ Pilot work suggested that adults assume the source of illumination to be at the top of a picture whether the picture is oriented vertically or horizontally, but that young children respond lawfully only when the picture is vertical. Therefore, a second question asked by this experiment was whether the photograph had to be oriented vertically for young children to perceive the differential shapes.

\section{Method}

\section{Subjects}

Thirty middle-class children from a Minneapolis, Minnesota. nursery school served as $\mathrm{Ss}$ in this experiment. Their ages ranged from 37 to 47 months, with a mean of 43 months.

\section{Procedure}

The Ss were first trained to discriminate haptically the convexity from the concavity on the copper rectangle used in the previous study. Correct responses were rewarded with an II\&II candy during training. The Ss reached underneath a curtain that blocked their view of the stimulus and were told to "find the bump." No learning was required, and all Ss reached the criterion of six consecutive correct choices immediately. To discourage positional responding and alternation, $\mathbf{E}$ emphasized that the position of the shapes changed on some but not on all trials. After haptic training, Ss were told. "Now we will look at a picture of the bump and hole. Which one is the bump?" They responded by pointing and were told. "Good," after every trial. As in Experiment I. two photographs were presented in a random order. In one. the shape with the top brightly lit was on the right. and in the other. it was on the left. All 30 Ss were tested with the picture held approximately 15 in. from the eve. For 15 of them. it was held vertically at eye level. and for the others. it was oriented horizontally. approximately 15 in. below eye level.

\section{Results}

The mean percentage of errors when the picture was oriented vertically was $14.6 \%$. This was less than half the error rate of the 3-year-olds in the previous experiment. Furthermore. 11 of the 15 had nearly perfect performances. They made no more than two incorrest 
choices in 20 trials. which was significantly higher than chance for each $S(p<.01$ by a sign test). The other four $S$ s responded very nearly at chance, making errors on approximately half of the trials.

In striking contrast, when the picture was oriented horizontally, the mean percentage of error was $49.3 \%$. None of the $15 \mathrm{Ss}$ responded at a level significantly higher than would be expected by chance. The difference in number of Ss responding above chance vs the number responding at chance level was significantly different in the horizontal and vertical conditions $\left[\chi^{2}(1)\right.$ $=16.4, \mathrm{p}<.001]$.

\section{Discussion}

It is clear that 3-year-olds are sensitive to light and shade information for depth in pictures. In addition, it is likely that there is no improvement with age. The four Ss who did not show any sensitivity were not younger than those who did. It also seems likely that the poor performance of many 3-year-olds in Experiment I was due to the difficulty of the discrimination training used.

The orientation of the photograph relative to gravity and the room lighting determined whether shading provided information for the differential shapes. Sensitivity was present when the pictures were oriented vertically and absent when they were horizontal, even though the relationship to the S's head was the same. It is possible that room lighting may affect where Ss "assume" the source of illumination in a picture to be, but this seems unlikely (Von Fieandt, 1938, 1949). An informal study using as Ss 15 employees of the Institute of Child Devetopment, University of Minnesota, revealed that when Fig. 1 is horizontal adults "assume" the source of illumination to be at the top of the picture. When viewing the two forms, they consistently reported that the convex form was the one whose brightly lit side was oriented toward the top of their heads (although some reported that the effect was stronger when the picture was oriented vertically rather than horizontally). The reader may satisfy himself by viewing Fig. 1 in both orientations. The results of Experiment II suggest that when viewing a horizontal picture, 3-year-olds do not "assume" that the source of illumination is at the top of the picture. Perhaps the ability to employ a spatial reference system other than the gravitational one in viewing a picture develops with age. Further work is needed to establish what information specifies the source of illumination for young $S s$ and adults.

\section{EXPERIMENT III}

In the previous studies, we found that for 3-year-olds the relationship between shading and the spatial reference system can provide information for depth. This study examines a second set of pictorial cues: linear perspective and vertical position on the picture plane. In the first experiment, a fine-grained photographic print was presented in a viewing box to decrease the likelihood that Ss would notice that the stimulus was artificial. In the second experiment, $E$ emphasized that a picture was being viewed and the $S$ actually touched its surface, but responsiveness to shading information for depth was not reduced. In this experiment, an even more artificial display, a line drawing with no texture or shading, was used to determine if young children can respond to a pictorial cue in a very unrealistic display. Hochberg and Brook's (1962) results suggest that a line drawing can be effective, as does some work with illusions (Pick \& Pick, 1970). On the other hand, Wilcox and Teghtsoonian (1971) found that pictorial depth cues did not control perception of size of equal retinal area figures in 3-year-olds. This was the case whether line drawings or realistic photographs were presented to the children. Similarly, Leibowitz and Judisch (1967) report that the Ponzo illusion is essentially nonexistent for children 3.5 to 4.7 years of age. ${ }^{3}$

In this experiment, a similar display, Gibson's line drawing of three identical-area cylinders positioned at three distances in a hallway (1950), was shown to 3-year-olds. For adults, this drawing provides a strong perception that the "far" cylinder is much larger than the "near" cylinder.

In our initial attempt to assess sensitivity to linear perspective, 22 3-year-old nursery school children were shown a vertical copy of the Gibson drawing, held approximately 15 in. from them, and asked if they saw three blocks in the picture. When they said, "Yes," they were asked, "Which one's the big one?" Nineteen of the children reported that the pictorially "farthest" cylinder was the big one and three chose the middle one. Although this suggests that 3-year-olds are sensitive to linear perspective, it is also possible that depth was not being detected. Since the "farthest" cylinder was also the highest in the picture plane and we do not know that these Ss understood the meaning of the word "big" in the same way adults do, it is possible that their responses only indicate which of the cylinders was highest on the picture plane. To rule out this possibility. Ss were asked to choose the "fat" one and the orientation of the picture was rotated $180 \mathrm{deg}$. Thus, the effect of having the pictorially "far" cylinder be the one with the lowest terminal point on the picture plane could be measured. In addition, Ss were run with the line drawing of the hallway omitted to see if position on the picture plane could be an effective cue for depth in the absence of linear perspective information.

\section{Method}

\section{Subjects}

Thirty-two nursery school children from a middle-class neighborhood in Minneapolis, Minnesota, served as Ss in this experiment. They ranged in age from 38 to 47 months, with a mean age of 42 months. 


\section{Design}

Sixteen of the Ss viewed a copy of the Gibson drawing of three cylinders in a hallway. The other 16 viewed a drawing of the cylinders in the same position they occurred in the Gibson drawing, but with the perspective drawing of the hallway omitted. Both groups were given two trials: one with the drawing in an upright orientation. and one in which the picture was rotated $180 \mathrm{deg}$ so that the pictorially "farthest" cylinder had the lowest terminal point. The order of the trials was counterbalanced.

\section{Procedure}

The $\mathrm{S}$ was presented with a line drawing held vertically about 15 in. away and asked if he saw three blocks. He was then asked, "Which one is the fat one?" His choice was recorded. and the question was asked again with the drawing rotated.

\section{Results}

The number of Ss who chose each of the three cylinders as fattest when the drawing was presented in an upright orientation (with the "farthest" cylinder in the highest position on the picture plane) is presented in Table 2. With linear perspective information for depth present, 14 of the 16 Ss chose the pictorially "farthest" cylinder. When perspective information was removed, the children showed no preference for the cylinder with the highest position on the picture plane. A chi-square test revealed a significant effect of the presence of linear perspective $\left[\chi^{2}(2)=12.7, p<.01\right]$. Orienting the drawing so the pictorially "farthest" cylinder was lowest in the picture plane did not significantly affect the number of Ss who responded to the "farthest" cylinder (see Table 2). Thirteen of the 16 children chose this cylinder when the drawing was rotated. Again, when perspective information was removed. the three cylinders were chosen with approximately equal frequency. There was a significant difference in the number of children choosing each cylinder when the presence of perspective information was varied $\left[\chi^{2}(2)=\right.$ 8.12. $\mathrm{p}<.02]$.

\section{Discussion}

Three-year-olds show a clear sensitivity to linear perspective information for depth in the Gibson drawing. This information controlled the children's perception of size of equal retinal area figures. On the other hand. the position of an object on the picture plane in the absence of perspective information for depth is not an effective cue for 3-year-olds.

This is also true for adults. Ten employees of the Institute of Child Development. University of Minnesota. were shown the drawing of the three cylinders without the perspective drawing of the hallway. When asked which was the fat one, they all reported that they were the same. When shown the original Gibson drawing. all agreed that the "far" one looked fattest.

There are several possible reasons why Wilcox and
Table 2

Number of Ss Choosing Each of Three Cylinders as "Fattest"

\begin{tabular}{|c|c|c|c|c|}
\hline \multirow{3}{*}{$\begin{array}{l}\text { Apparent } \\
\text { Position } \\
\text { of Chosen } \\
\text { Cylinder }\end{array}$} & \multicolumn{2}{|c|}{ Display Lpright } & \multicolumn{2}{|c|}{$\begin{array}{c}\text { Display } \\
\text { Rotated } 180 \text { Deg }\end{array}$} \\
\hline & \multicolumn{2}{|c|}{$\begin{array}{l}\text { Perspective } \\
\text { Information }\end{array}$} & \multicolumn{2}{|c|}{$\begin{array}{l}\text { Perspective } \\
\text { Information }\end{array}$} \\
\hline & Present & Absent & Present & Absent \\
\hline Searest & 1 & 7 & 2 & 7 \\
\hline Middle & 1 & 5 & 1 & 4 \\
\hline Farthest & 14 & 4 & 13 & 5 \\
\hline
\end{tabular}

Teghtsoonian (1971) found no sensitivity to pictorial depth information in 3-year-olds while this study did. The finding that young children have a tendency to attend to information for the two-dimensional surface of a picture while adults tend to ignore the picture plane and respond to pictorial depth (Yonas \& Hagen, in press) may play a part in the explanation, but it alone cannot account for the discrepancy. Information for the picture plane was present in our series of experiments, and yet sensitivity to pictorial depth was demonstrated. Another possible source of the difference in the results was the procedure. Our instructions may have directed the attention of the Ss to pictorial depth, while the method of Wilcox and Teghtsoonian (1971) allowed their Ss to attend to the flat picture plane. In addition, Wilcox and Teghtsoonian used a long operant conditioning procedure, while in these experiments, the length of the task was kept to a minimum. Arguing against this possibility, Wilcox and Teghtsoonian found that 3-vear-olds responded differentially to figures unequal in retinal area throughout their long testing procedure.

The third and most likely explanation for the discrepancies may lie with differences in the pictures used. According to Gibson (1950), the amount of surface occluded by an object as it rests on a surface provides information for perception of size. In this experiment, the cylinders had a strong three-dimensional appearance and clearly appeared to be either resting on the floor of the hallway or attached to its ceiling. In the Wilcox and Teghtsoonian study, two-dimensional shapes were used and they may well have had a tendency to appear to float rather than rest on the surface. Perhaps young children are less likely than adults to assume that objects in a picture are resting on a surface. This is a question for future research to investigate.

\section{CONCLUSION}

In conclusion, children as young as 3 years of age are quite sensitive to static depth information provided by (1) the relationship between shading and some spatial reference system and (2) linear perspective information. The question of whether this sensitivity is innate or develops will have to be answered with younger Ss than those who took part in this study. 


\section{REFERENCES}

Bower. T, G. R. Discrimination of depth in premotor infants. Psychonomic Science, 1964, 1, 368.

Bower. T. G. R. Stimulus variables determining space perception in infants. Science, $1965,149,88-89$.

Bower, T, G. R. The visual world of infants. Scientific American, 1966, 215, 80-92.

Gibson. J. J. Perception of the visual world. Boston: Houghton Mifflin. 1950.

Guenther, W. C. Analysis of variance. Englewood Cliffs: Prentice-Hall, 1964. Pp. 57-58.

Hershberger, W. Attached-shadow orientation perceived as depth by chickens reared in an environment illuminated from below. Journal of Comparative \& Physiological Psychology, 1970, 73, $407-411$.

Hess. E. H. Development of the chick's responses to light and shade cues of depth. Journal of Comparative \& Physiological Psychology, 1950, 43, 112-122.

Hochberg, J. E. Nativism and empiricism in perception. In L. Postman (Ed.), Psychology in the making. New York: Knopf, 1962. Pp. 255-330.

Hochberg, J. E., \& Brooks, V. Pictorial recognition as an unlearned ability: A study of one child's performance. American Journal of Psychology, 1962, 75, 624-628.

Leibowitz, H. W., \& Judisch, J. M. The relation between age and the magnitude of the Ponzo illusion. American Joumal of Psychology, 1967, 80, 105-110.

Metzger, W. Gesetze des Sehens. Frankfurt: Kramer, 1936.

Pick, H. L., \& Pick. A. D. Sensory and perceptual development. In P. H. Mussen (Ed.). Carmichael's manual of child psycholog: New York: Wiley, 1970. Pp. 773-848.
Von Fieandt. K. Ueber Sehen von Tiefengebilden bei Wechseln der Beleuchtungsrichtung. Helsinki: Psychological Institute of the University of Helsinki, 1938.

Von Fieandt. K. Das phönomenologische Problem von Licht und Schatten. Acta Psychologica, 1949, 6, 337-357.

Wilcox, B. L., \& Teghtsoonian, M. The control of relative size by pictorial depth cues in children and adults. Journal of Experimental Child Psychology, 1971, 11, 413-429.

Yonas, A., \& Hagen, M. Effects of static and kinetic information of depth. Journal of Experimental Child Psychology. in press.

\section{NOTES}

1. By saying Ss "assume" a source of illumination, we do not mean a conscious intellectual decision is being made, but rather that the visual system is functioning as though illumination were from above. One can consciously assume that light is coming from below with little effect on experience.

2. These facts suggest that sensitivity to shading is innate and also argue that such a sensitivity should function only when vertical surfaces are being viewed.

3. It should be noted that although Leibowitz and Judisch (1967) found an increase in the magnitude of the illusion with age, the conclusion that the illusion is absent in young children can be criticized on two counts. First, the conclusion requires that the null hypothesis be accepted. Second, only the boys failed to show a significant effect. For the girls, the effect was small, but larger than would be expected by chance $[t(9)=2.12$, $\mathrm{p}<.05$, one-tailed, author's computation).

(Received for publication September 22, 1972; revision received December 27.1972 .) 